động hô hấp. ${ }^{4,7,8}$ Chính vì vậy để đề phòng biến chứng này, chúng tôi chủ động gia cố thành ngực bằng tấm mesh che phủ kết hợp với vạt da - cơ lưng rộng ở bệnh nhân của mình. Kroll và cộng sự báo cáo rằng 40 bệnh nhân được phẫu thuật tạo hình thành ngực có sử dụng mesh kết hợp với vạt có sự hồi phục tốt hơn hẳn cùng với thời gian hố trợ hô hấp ngắn hơn và thời gian nằm viện ngắn hơn so với việc chỉ dùng vạt đơn thuần. ${ }^{9}$ Chang và cộng sự cũng đưa ra kinh nghiệm rằng nên sử dụng tấm mesh kết hợp khi loại bỏ từ 4 xương sườn trở lên hoặc nếu tổn thương thành ngực diện rộng lan tới vùng thượng vị. ${ }^{5}$

\section{KẾT LUÂN}

Tao hình thành ngực do viêm loét sau xạ trị là một thách thức đối với các nhà lâm sàng tại Việt Nam cũng như trên thế giới hiện nay. Việc lựa chọn phương pháp điều trị cũng còn nhiều tranh cãi, phụ thuộc vào nhiều yếu tố như vị trí, mức độ tổn thương tại chỗ toàn trạng bệnh nhân, kinh nghiệm của phầu thuật viên...Sử dụng vạt da - cớ lưng rộng được coi là phương pháp phổ biến và ưa dùng hơn cả bởi tính linh hoạt và an toàn của nó. Bên cạnh đó, để đạt được kết quả tốt sau mổ, phẫu thuật viên cần đảm bảo tính an toàn về mặt ung thư học cũng như tính thẩm mỹ và đặc biệt là chức năng thành ngực cho người bệnh.

TÀI LIỆU THAM KHẢO
1. Zhou $\mathbf{Y}$, Zhang $\mathbf{Y}$. Single- versus 2-stage reconstruction for chronic post-radiation chest wall ulcer: A 10-year retrospective study of chronic radiation-induced ulcers. Medicine (Baltimore). Feb 2019;98(8):e14567.

MD.0000000000014567

doi:10.1097/

2. Arnold PG, Pairolero PC. Reconstruction of the radiation-damaged chest wall. Surg Clin North Am. Oct 1989;69(5):1081-9. doi:10.1016/s00396109(16)44939-x

3. Beahm EK, Chang DW. Chest wall reconstruction and advanced disease. Semin Plast Surg. May 2004;18(2):117-29. doi:10.1055/s-2004-829046

4. Hameed A, Akhtar S, Naqvi A. Reconstruction of complex chest wall defects by using polypropylene mesh and a pedicled latissimus dorsi flap: a 6-year experience. J Plast Reconstr Aesthet Surg. Jun 2008;61(6):628-35. doi:10.1016/ j.bjps.2007.04.011

5. Chang RR, Mehrara BJ, Hu QY. Reconstruction of complex oncologic chest wall defects: a 10-year experience. Ann Plast Surg. May 2004;52(5):4719; discussion 479. doi:10.1097/ 01.sap. $0000122653.09641 . f 8$

6. Mittal $S$, Singh $B$, Uppal $M$. Chest wall reconstruction using Latismus Dorsi Flap: our experience. International Surgery Journal. 2017:4(8)

7. Devianti M, Mukarramah D, Rini I. Modalities for Chest Wall Reconstruction Following Cancer Ablation: A Single Center Experience. International Microsurgery Journal. 2019;3(2):5.

8. Arnold PG Pairolero PC. Chest-wall reconstruction: an account of 500 consecutive patients. Plast Reconstr Surg. Oct 1996;98(5):80410. doi:10.1097/00006534-199610000-00008

9. Kroll SS, Walsh G, Ryan B. Risks and benefits of using Marlex mesh in chest wall reconstruction. Ann Plast Surg. Oct 1993;31(4):303-6. doi:10.1097/00000637-199310000-00003

\title{
NGHIÊN CỨU ĐÁNH GIÁ CHỨC NĂNG THẤT PHẢI TRÊN SIÊU ÂM DOPPLER TIM Ở BÊ̂NH NHÂN HỞ' HAI LÁ MAN TÍNH TRƯớC VÀ SAU PHẪU THUÂ̂T THAY VAN HOẶC SỬA VAN HAI LÁ
}

\section{Nguyễn Đoàn Trung*, Nguyễn Thị Thu Hoài*, Nguyễn Thị Bạch Yến*}

\section{TÓM TẮT}

Mục tiêu: Đánh giá chức năng thất phải trên siêu âm Doppler tim ở bệnh nhân hở hai lá mạn tính trước và sau phẫu thuât thay van hoăc sửa van hai lá tai Viện Tim mạch Việt Nam. Phương pháp nghiên cứu: Nghiên cứu của chúng tôi được thực hiên trên38 bệnh nhân hở hai lá thực tổn có chỉ định phẫu thuật theo khuyến cáo xử trí hở van hai lá (theo AHA/ACC

*Viên Tim mach Viêt Nam - Bênh viên Bach Mai

Chịu trách nhiệm chính: Nguyển Đoàn Trung

Email: nguyendoantrung88@gmail.com

Ngày nhận bài: 14.9.2021

Ngày phản biên khoa hoc: 15.11.2021

Ngày duyệt bài: 24.11.2021
2017 hoăc của Hội Tim mạch Việt Namnếu có), các bệnh nhẩn được phẫuthuật tại đơn vị phẫu thuật Viện Tim Mach. Tất cả các bênh nhân đều được thu thâp số liệu về đặc điểm lâm sàng, cận lâm sàng và kết quả can thiệp mach vành, kết quả siêu âm tim đánh giá các thông số nghiên cứu. Kết quả nghiên cứu: Chỉ số tei thất phải xung trước phẫu thuật $(0,42 \pm 0,05)$ và chỉ số tei thất phải mô trước phẫu thuật $(0,52 \pm$ $0,04)$ cho thấy có sự khác biệt đáng kể so với chỉ số sau phâuu thuật $(0,36 \pm 0,02$ và $0,44 \pm 0,04)$. Về chức năng tâm thu thất phải: Vận tốc vòng van 3 lá trước và sau phâu thuật khác nhau có ý nghĩa thống kê $(17,45 \pm 0,98$ và $20,38 \pm 3,48)$. Vận tốc sóng $S^{\prime}$ trên Doppler mô của đối tượng nghiên cứu có giá trị trung bình sau phẫu thuật tăng lên so với trước phẫu thuật $(8,86 \pm 0,55$ và $11,4 \pm 3,14)$. Chỉ số diện tích thất 
phải (FAC) của đối tượng nghiên cứu tăng lên sau phẫu thuật $(35,45 \pm 1,48$ và $39,86 \pm 5,02)$. Kết luâan: Trên bệnh nhân hở van 2 lá mạn tính, chức năng thất phải sau phẫu thuật có sự cải thiện so với trước phẫu thuật

Ti̛ khóa: Siêu âm tim, hở hai lá nặng mạn tính, phẫu thuật thay hoặc sửa van hai lá, chức năng thất phải trên siêu âm doppler tim

Tư viêt tắt: HoHL: hở van hai lá, TAPSE: vân động vòng van ba lá trong thì tâm thu, FAC: phẩn xuất diện tích thất phải, $S^{\prime}$ : sóng $S$ tâm thu của Doppler mô vận động vòng van ba lá, Tei: chỉ số vận động cơ tim, ALĐMP: áp lực động mạch phổi

\section{SUMMARY}

\section{TO EVALUATE RIGHT VENTRICULAR FUNCTION ON CARDIAC DOPPLER ECHOCARDIOGRAPHY IN PATIENTS WITH CHRONIC MITRAL REGURGITATION BEFORE AND AFTER VALVE \\ REPLACEMENT OR MITRAL VALVE REPAIR}

Objective: To evaluate right ventricular function on cardiac Doppler echocardiography in patients with chronic mitral regurgitation before and after valve replacement or mitral valve repair at the Vietnam Heart Institute. Methods: Our study was carried out on 38 patients with true mitral regurgitation with indications for surgery according to the recommendations for management of mitral regurgitation (according to AHA/ACC 2017 or the Vietnam Heart Association if required). yes), the patients were operated on at the Cardiology Institute surgical unit. All patients were collected data on clinical characteristics, subclinical and coronary intervention results, echocardiographic results to evaluate research parameters. Results: Preoperative right ventricular atrophy index $(0.42 \pm 0.05)$ and preoperative right ventricular atrophy index $(0.52 \pm$ 0.04 ) showed a significant difference compared with the postoperative index $(0.36 \pm 0.02$ and $0.44 \pm$ $0.04)$. About right ventricular systolic function: Tricuspid annulus velocity before and after surgery was statistically significant $(17.45 \pm 0.98$ and $20.38 \pm$ 3.48). The $S^{\prime}$ wave velocity on the tissue Doppler of the study subjects had an increased mean value after surgery compared to before surgery $(8.86 \pm 0.55$ and $11.4 \pm 3.14$ ). Right ventricular area index (FAC) of the study subjects increased after surgery $(35.45 \pm 1.48$ and $39.86 \pm 5.02)$. Conclusion: In patients with chronic mitral regurgitation, the right ventricular function after surgery has improved compared to before surgery.

Keywords: Echocardiography, chronic severe mitral regurgitation, mitral valve replacement or repair surgery, right ventricular function on echocardiography

Acronyms: HoHL: mitral regurgitation, TAPSE: tricuspid annulus movement during systole, FAC: right ventricular area fractionation, $S^{\prime}$ : systolic $S$ wave of Doppler tricuspid motor tissue, Tei: index myocardial exercise, ALPMP: pulmonary artery pressure

\section{I. ĐĂT VẤN ĐỀ}

Hở van hai lá (HoHL) là tình trạng khi có luồng máu trào ngược từ thất trái lên nhĩ trái do van hai lá đóng không kín trong thời kỳ tâm thu. $\mathrm{HOHL}$ được phân thành 2 loại chính là $\mathrm{HOHL}$ thực tổn và $\mathrm{HOHL}$ cơ năng (khổng do tổn thương bộ máy van hai lá). HoHL thực tổn là một bệnh lý khá thường gặp với thương tổn đặc trưng của một hay nhiều thành phần của bộ máy van hai lá (mô van, vòng van, bộ máy dưới van). Tỉ lệ HoHL thực tổn khá phổ biến từ 5-24\% trong tổng số các bệnh lý tim mạch ${ }^{1}$.

Thay đổi của chức năng thất phải và vai trò của các thông số chức năng thất phải ở các bệnh nhân bệnh tim trái trước đây còn ít được quan tâm. Gần đây cùng với sự tiến bộ của các kỹ thuật siêu âm tim, nhiều thông số đánh giá chức năng thất phải đã được nghiên cứu và ứng dụng trên lâm sàng. Một số thông số chức năng thất phải đã được chứng minh là yếu tố tiên lượng biến cố và tử vong ở các bệnh nhân nhồi máu cơ tim cấp, bệnh nhân suy tim mạn, tăng áp ĐMP2

Câu hỏi đặt ra là ở các BN hở hai lá, chức năng thất phải có bị ảnh hưởng hay không? Những yếu tố nào có tác động đến chức năng TP và suy giảm chức năng thất phải có liên quan đến tiên lượng ở các bệnh nhân nay hay không? Đã có một số NC trên thế giới về chức năng thất phải ở bệnh nhân hở hai lá nặng, mạn tính thực tổn, Kết quả cho thấy suy giảm chức năng tâm thu thất phải gặp ở 30\% các BN hở hai lá nặng mạn tính và $16 \%$ các bệnh nhân này có suy chức năng cả 2 thất. Có liên quan giữa chức năng tâm thu thất phải với chức năng vách liên thất, đường kính cuối tâm trương thất trái và áp lực động mạch phổi tâm thu. Một số nghiên cứu khác cũng cho thấy chỉ số chức năng tâm thu TP có liên quan với ALĐMP. Tuy nhiên một nghiên cứu khác gần đây cho thấy suy thất phải (EF/TP $\leq 35 \%$ ) là yếu tố tiên lượng độc lập sống sót sau 10 năm (sau khi điều chỉnh với các yếu tố tiên lượng đã biết) ở các bệnh nhân hở hai lá thực tổn, nặng, mạn tính ${ }^{3}$.

ở Việt nam đã có nhiều nghiên cứu về chức năng thất trái ở các bệnh nhân hở hai lá, tuy nhiên còn ít nghiên cứu về chức năng thất phải ở các bệnh nhân này được công bố.

Chính vì vậy, chúng tôi tiến hành nghiên cứu nhằm bước đâuu tìm hiểu những thay đổi của chức năng thất phải ở những bệnh nhân hở van 2 lá mạn tính được tiến hành phẩu thuật.

\section{II. Đốl TƯợNG VÀ PHƯƠNG PHÁP NGHIÊN CỨU}

Trong thời gian từ tháng 7/2020 đến 7/2021, đối tượng nghiên cứu của chúng tôi bao gồm các bệnh nhân được chẩn đoán hở hai lá thực tổn mức độ nặng mạn tính có chỉ định phẫu thuật 
theo khuyến cáo xử trí hở van hai lá (theo AHA/ACC 2017 hoặc của Hội Tim mạch Việt nam nếu cố) , các bệnh nhân được phẫu thuật tại đơn vị phẫu thuật Viện Tim Mạch. Tất cả các bệnh nhân đều được thu thập số liệu về đặc điểm lâm

\section{KẾT QUẢ NGHIÊN CỨU}

3.1. Đăc điểm chung của nhóm đối tượng nghiên cứu

Bảng 4. Đặc điểm chung của đôi tượng nghiên cứu

\begin{tabular}{|c|c|c|c|c|c|}
\hline & $\mathbf{N}$ & Trung bình & DLC & Tối thiếu & Tối đa \\
\hline Tuối (năm) & 38 & 56,8 & 4,9 & 46 & 69 \\
\hline Chiều cao $(\mathrm{cm})$ & 38 & 58 & 5,4 & 52 & 78 \\
\hline Cân nặng (kg) & 38 & 167,9 & 2,7 & 163 & 172 \\
\hline BMI $\left(\mathrm{kg} / \mathrm{m}^{2}\right)$ & 38 & 20,1 & 1,6 & 18,0 & 26,7 \\
\hline $\operatorname{BSA}\left(\mathrm{m}^{2}\right)$ & 38 & 1,6 & 0,1 & 1,56 & 1,89 \\
\hline & & & \multicolumn{2}{|c|}{ Số lương } & Tí lệ \\
\hline Giới tính & & Nữ & \multicolumn{2}{|c|}{15} & $39.5 \%$ \\
\hline & & Nam & \multicolumn{2}{|c|}{23} & $\%$ \\
\hline
\end{tabular}

Độ tuổi trung bình trong nghiên cứu 56,8 土 4,9 và nam giới chiếm 60,5\%

\section{2. Đăcc điểm hở van hai lá mạn tính}

Bảng 5. Nguyên nhân và phân loại của hở van hai lá mạn tính

\begin{tabular}{|c|c|c|}
\hline Nguyên nhân & Số lượng & Tỉ lệ (\%) \\
\hline Sa van hai lá & 27 & $67,5 \%$ \\
\hline Viêm nội tâm mạc nhiêm khuấn & 4 & $10,0 \%$ \\
\hline Khác (đứt dây chằng van ) & 9 & $22,5 \%$ \\
\hline \multicolumn{2}{|c|}{ Phân loại tốn thương HoHL } \\
\hline HoHL type I \\
\hline HoHL type IIa & 3 & $5.6 \%$ \\
\hline HoHL type IIb & 30 & $58.8 \%$ \\
\hline HoHL type IIIa & 14 & $27.5 \%$ \\
\hline HoHL type IIIb & 4 & $7.8 \%$ \\
\hline HoHl type IIIc & 0 & $0.0 \%$ \\
\hline Tống & 0 & $0.0 \%$ \\
\hline
\end{tabular}

Sa van 2 lá là nguyên nhân hơ 2 lá mạn tính thường gặp nhất. Tốn thương thường gặp nhất là HoHL type IIa, IIb (chiếm 58,8 và 27,5\%).

Bảng 6. Đặc điểm đánh giá dòng hở van hai lá trên siêu âm tîm

\begin{tabular}{|c|c|c|c|c|c|}
\hline & Số lượng & Trung bình & $\mathbf{\pm ~ S D}$ & Tối thiếu & Tối đa \\
\hline Vena contracta (mm) & 38 & 8,8 & 0,8 & 7,1 & 10,3 \\
\hline Diện tích hở hai lá (cm2) & 38 & 12,3 & 2,5 & 9,5 & 18,9 \\
\hline Diện tích HoHL/diện tích NT & 38 & 0,4 & 0,0 & 0,4 & 0,6 \\
\hline Thế tích nhĩ trái (ml)(LAVI) & 38 & 57,7 & 19,2 & 36,0 & 116,0 \\
\hline Diện tích lố hơ hiệu dụng (ERO) (mm $\left.{ }^{2}\right)$ & 38 & 0,8 & 0,1 & 0,5 & 0,9 \\
\hline Chiều dài lá trước (mm) & 38 & 31,8 & 2,5 & 26,0 & 38,0 \\
\hline Đường kính trước sau vòng VHL (mm) & 38 & 36,6 & 2,4 & 30,0 & 39,0 \\
\hline Đường kính ngang vòng VHL (mm) & 38 & 34,9 & 3,3 & 20,0 & 38,9 \\
\hline
\end{tabular}

3.3. Sự thay đối chức năng thất phải trước và sau phâuu thuật

Bảng 7. Sự thay đổi chức năng thất phải trước và sau phấu thuật

\begin{tabular}{|c|c|c|c|}
\hline & Trước PT & Sau PT & $\mathbf{p}$ \\
\hline \multicolumn{4}{|c|}{ Chức năng toàn bộ } \\
\hline Chỉ số Tei thất phải & $0.42 \pm 0.05$ & $0.36 \pm 0.02$ & 0.000 \\
\hline Chỉ số Tei mô thất phải & $0.52 \pm 0.04$ & $0.44 \pm 0.04$ & 0.000 \\
\hline \multicolumn{4}{|c|}{ Chức năng tâm thu } \\
\hline Vận động vòng van 3 lá (TAPSE) & $17.45 \pm 0.98$ & $20.38 \pm 3.48$ & 0.000 \\
\hline Vận tốc sóng $S^{\prime}$ trên Doppler mô & $8.86 \pm 0.55$ & $11.4 \pm 3.14$ & 0.000 \\
\hline Chỉ số diện tích thất phải (FAC) & $35.45 \pm 1.48$ & $39.86 \pm 5.02$ & 0.000 \\
\hline
\end{tabular}




\begin{tabular}{|c|c|c|c|}
\hline \multicolumn{4}{|c|}{ Chức năng tâm trương } \\
\hline Sóng E qua van 3 lá doppler xung $(\mathrm{cm} / \mathrm{s})$ & $7.74 \pm 0.56$ & $8.76 \pm 5.07$ & 0.220 \\
\hline Sóng A qua van 3 lá doppler xung(cm/s) & $8.61 \pm 0.43$ & $8.7 \pm 1.37$ & 0.635 \\
\hline Tì lệ E/A qua van 3 lá & $1.1 \pm 1.38$ & $1.09 \pm 1.31$ & 0.964 \\
\hline Sóng $E^{\prime}$ qua van 3 lá doppler mô $(\mathrm{m} / \mathrm{s})$ & $7.45 \pm 0.46$ & $7.83 \pm 1.19$ & 0.062 \\
\hline Sóng A' qua van 3 lá doppler mô $(\mathrm{m} / \mathrm{s})$ & $8.7 \pm 0.46$ & $8.97 \pm 0.46$ & $\mathbf{0 . 0 0 2}$ \\
\hline Tí lệ E/E' qua van 3 lá & $0.88 \pm 0.07$ & $1.33 \pm 1.86$ & 0.152 \\
\hline Diện tích nhĩ phải & $17.83 \pm 1.15$ & $16.9 \pm 2.76$ & $\mathbf{0 . 0 4 8}$ \\
\hline Ap lực động mạch phổi $(\mathrm{mmHg})$ & $30.83 \pm 0.94$ & $29.25 \pm 2.32$ & $\mathbf{0 . 0 0 1}$ \\
\hline Vậnn tô̂́c qua van 3 lá $(\mathrm{m} / \mathrm{s})$ & $40.76 \pm 5.61$ & $31.22 \pm 3.09$ & $\mathbf{0 . 0 0 0}$ \\
\hline
\end{tabular}

So với trước phẫu thuật, chức năng thất phải sau phầu thuật có những cải thiện ở chức năng thất phải toàn bộ (biểu hiện qua chỉ số Tei), chức năng tâm thu và chức năng tâm trưởng.

\section{BÀN LUẬN}

Hở van hai lá (HoHL) là tình trạng khi có luồng máu trào ngược từ thất trái lên nhĩ trái do van hai lá đóng không kín trong thời kỳ tâm thu. Do đó, về lâu dài, nếu không được điêu trị hợp lý, bệnh lý này có thể dẫn đến những rối loạn chức năng tâm thu, chức năng tâm trương và cuối cùng là suy tim trái. Tuy vậy, bên cạnh những tác động đến tim trái, hở hai lá cũng có những tác động bệnh lý gián tiếp đến hoạt động thất phải, và kết cục lâu dài cũng gây ra tình trạng tăng áp phổi và suy thất phải. Do đo, khi được điều trị kịp thời sẽ mang đến những cải thiện về mặt huyết động và chức năng cho bệnh nhẩn. Theo kết quả nghiên cứu của chúng tôi, chức năng thất phải sau phẫu thuật ở những bệnh nhân hở hai lá mạn tính cho thấy những cải thiện đáng ghi nhận:

Về chức năng thất phải toàn bộ: Chỉ số tei thất phải xung trước phâuu thuật $(0,42 \pm 0,05)$ và chỉ số tei thất phải mô trước phẩu thuật $(0,52 \pm$ $0,04)$ cho thây có sự khác biệt đáng kể so với chỉ số sau phẫu thuật $(0,36 \pm 0,02$ và $0,44 \pm 0,04)$.

Về chức năng tâm thu thất phải: Vận tốc vòng van 3 lá trước và sau phẫu thuật khác nhau có ý nghĩa thống kê $(17,45 \pm 0,98$ và $20,38 \pm$ $3,48)$. Vận tốc sóng $S^{\prime}$ trên Doppler mô của đối tượng nghiên cứu có giá trị trung bình sau phẫu thuật tăng lên so với trước phẫu thuật $(8,86 \pm$ $0,55$ và $11,4 \pm 3,14)$. Chỉ số diện tích thất phải (FAC) của đối tượng nghiên cứu tăng lên sau phẫu thuật $(35,45 \pm 1,48$ và $39,86 \pm 5,02)$.

Một nghiên cứu khác của Chrustowicz ${ }^{4}$ và cộng sự vào năm 2010 được thực hiện trên 45 bệnh nhân với hở van hai lá nguyên phát mức độ nặng được phẫu thuâat. TAPSE và Sa trung bình trước phẩu thuật lần lượt là $19,4 \pm 4,3 \mathrm{~mm}$ và $10,3 \pm 3$ $\mathrm{cm} /$ giây. Rối loạn chức năng TP, được định nghĩa là TAPSE $<22 \mathrm{~mm}$, có $66,6 \%$ bệnh nhẩn, và $\mathrm{Sa}$ $<11 \mathrm{~cm} /$ giây được tìm thấy ở $62,2 \%$ bệnh nhân trước phẫu thuật. TAPSE trước phẫu thuật và Sa có tương quan có ý nghĩa $(P<0,00001, r=0,61)$. Cả TAPSE và Sa đều tương quan với đường kính cuối tâm trương TP $(P<0,01)$, LVESD $(P<0,05)$ $\mathrm{dp} / \mathrm{dt}$ thất trái $(P<0,05)$ và $\operatorname{LVEF}(P<0,0001)$. LVEF sau phẫu thuật là $50 \%(P<0,001)$, Sa 5,3 $+/-2 \mathrm{~cm} /$ giây $(P<0,001)$, và TAPSE $8,7+/-3,2 \mathrm{~mm}$ ( $P<0,001) .21$ bệnh nhân $(46,6 \%)$ đạt đến điểm cuối của nghiên cứu là giảm LVEF hơn $10 \%$.

Về chức năng tâm trương: Tỉ lệ E/A qua van 3 lá và tỉ lệ $E / E^{\prime}$ qua van ba lá không có khác biệt đáng kể trước và sau phẫu thuật, điều này có thể do chức năng thất phải chưa thể hiện cải thiện ngay sau phẩu thuật. Trong khi đó, diện tích nhĩ phải của các đối tượng nghiên cứu có giá trị trung bình giảm đi sau phẫu thuật $(17,83 \pm$ $1,15$ và $16,9 \pm 2,76 ; p=0,048)$. Áp lực động mạch phổi sau phẫu thuật của các đối tượng nghiên cứu có giá trị trung bình thấp hơn so với trước phẫu thuật $(29,25 \pm 2,32 \mathrm{mmHg}$ so với $30,83 \pm 0,94 \mathrm{mmHg}$ ). Vận tốc qua van 3 lá của các đối tượng nghiên cứu có giá trị trung bình sau phẫu thuật giảm đi so với lúc nhập viện $(31,22 \pm 3,09$ và $40,76 \pm 5,61)$.

Về chức năng thất phải sau phẫu thuật, năm 1991, J S Borer ${ }^{5}$ và cộng sự đã thực hiện nghiên cứu để xác định ý nghĩa bệnh học và giá trị lâm sàng của việc đánh giá chức năng thất phải trong bệnh hở van hai lá. Phẫu thuật thay van được thực hiện ở 22 bệnh nhân hở van hai lá đơn thuần; trong số sáu bệnh nhân có phân suất tống máu thất phải $\leq 30 \%$ trước khi mổ, chỉ 1 bệnh nhân tử vong $(P<0-05)$, cho thấy tác dụng giảm nguy cơ tử vong của phẫu thuật thay van. Trong số 8 bệnh nhân trước phẫu thuật có kết hợp hở van hai lá và van động mạch chủ, 4 bệnh nhân tử vong trong vòng 7 năm sau khi thay cả hai van; tất cả bệnh nhân có phân suất tống máu thất phải khi gắng sức $<20 \%$ tử vong. Sau khi thay van hai lá với bệnh nhân hở van hai lá đơn thuần, phân suất tống máu thất phải được cải thiện nhanh chóng (trung bình $8 \%$ trong $<1$ năm $(\dot{P}<0-05) ; 3 \%$ thêm vào 3 năm sau phẫu 
thuật $(P<0-05))$. Triệu chứng sau mổ có thể dự đoán được do phân suất tống máu tâm thất trước mố <30\% $(P<0-05)$. Cuối cùng, trong số những bệnh nhân không có hoăc có ít triêu chứng và phân số tống máu thất trái và thất phải bình thường khi nghỉ ngơi lúc bắt đầu nghiên cứu, tiên lượng các trường hợp có thể phẫu thuất được dự đoán tốt nhất bằng sự giảm phân suất tống máu thất phải khi vận động $(P<005)$. Do đó, thông số về chức năng thất phải là một yếu tố dự đoán nguy cơ chính và hữu ích trong việc ra quyết định xử trí trong trường hợp hở van hai lá mức độ năng, không do nhồi máu cơ tim 5 .

Nghiên cứu của Sun và cộng sự vào năm 2013 cũng cho thấy: Trong số 334 bệnh nhân trong nghiên cứu, 280 bệnh nhân có biểu hiện từ bình thường đến suy giảm chức năng thất phải nhẹ trước khi phẫu thuật (nhóm 1). Năm mươi bốn bệnh nhân bị rối loạn chức năng thất phải mức độ trung bình đến nặng (nhóm 2). Bệnh nhân có chức năng thất phải bị tổn thương có nhiều khả năng bị MVR hơn $(28,6 \%$ so với $53,7 \%$, P $<0,001)$. Áp lực động mạch phổi trung bình là $23,6 \mathrm{mmHg}$ ở nhóm 1 và $34 \mathrm{mmHg}$ ơ nhóm 2 (P $<0,001)$. Đường kính tâm nhĩ trái là $4,6 \mathrm{~cm}$ ở nhóm 1 và $5,3 \mathrm{~cm}$ ở nhóm $2(\mathrm{P}<0,001)$. Hai nhóm không khác nhau về Tỉ lệ tử vong do phẫu thuât, nhưng bênh nhân ở nhóm 2 được truyền nhiều chế phẩm máu hơn $(588,4 \mathrm{~mL}$ so với $1180,6 \mathrm{~mL}, \mathrm{P}<0,001)$, thời gian nằm tại phòng chăm sóc đặc biệt lâu hơn (83,9 so với 149,6 giờ, $\mathrm{P}<0,001)$, và thời gian nằm viện $(8,9$ so với 12,8 ngày, $\mathrm{P}=0,005)$. Tî lệ trào ngược $\mathrm{MV}$ sau mổ cao hơn đáng kể ở nhóm 2 (1,8 so với $14,8 \%, P$ $<0,001)$. Tỉ lệ sống thêm 1 năm chung là $92,5 \%$ ở nhóm 1 và $94,5 \%$ ở nhóm $2(\mathrm{P}=0,59)$. Nghiên cứu này đã chỉ ra rằng chức năng thất phải trước phẫu thuật bị rối loạn sử dụng nhiều nguồn lực hơn và có liên quan đến tình trạng MR sau phẫu thuật, nhưng nó không liên quan đến Tỉ lệ tử vong ngắn hạn và trung hạn sau phẫu thuật MV ${ }^{6}$.

Khi nghiên cứu về sự thay đổi chức nắng thất phải sau phẫu thuật, vào năm 2013, Le Tourneau ${ }^{3}$ và cộng sự đã tiến hành đo chức năng tâm thu thất phải trên hai trăm tám bệnh nhân (62 \pm 12 tuổi, 138 nam) bị hở van hai lá nguyên phát mãn tính có chỉ định phẫu thuật đã trải qua một siêu âm tim và chụp mạch phóng xạ tâm thất với đánh giá chức năng khu vực. Khi xem xét phân suất tống máu thất phải (TP EF) trung bình là $40,4 \pm 10,2 \%$, nằm trong khoảng từ $10 \%$ đến $65 \%$. TP EF suy giảm nghiêm trong ( $\leq 35 \%)$ ở 63 bệnh nhân (30\%), và suy hai thất (EF thất trái $<60 \%$ và $E F$ thất phải $\leq 35 \%$ ) được tìm thây ở 34 bệnh nhân (16\%). Ở 68 bệnh nhân khám sau phẫu thuật, TP EF tăng mạnh $(27,5 \pm 4,3-37,9 \pm 7,3, \mathrm{P}<0.0001)$ ở những bệnh nhân có TP $E F$ giảm nặng, trong khi nó không thay đổi ở những người khác $(P=0,91)$. TP EF $\leq 35 \%$ làm giảm thời gian sống thêm 10 năm với bệnh tim mạch $(71,6 \pm 8,4 \%$ so với $89,8 \pm 3,7 \%, P=0,037)$. Kết luận là với bệnh nhân hở van hai lá nguyên phát có chỉ định phẫu thuật hay có suy chức năng thất phải $(30 \%)^{3}$.

Đến năm 2014, trong nghiên cứu của Hyllen và cộng sự về chức năng thất phải làm trên 40 bệnh nhân có chỉ định phẫu thuật sửa van 2 lá theo dõi trong 6 tháng. Kết quả cho thấy sau phẫu thuật có $61 \%$ bệnh nhân giảm chức năng thất phải. Theo dõi các chỉ số chức năng thất phải thấy TAPSE giảm từ $24 \pm 5 \mathrm{~mm}$ xuống $15 \pm$ $3 \mathrm{~mm}, \mathrm{p}<0.001$ ), vận tốc đỉnh tâm thu giảm từ $14 \pm 3 \mathrm{~cm} / \mathrm{s}$ xuống10 $\pm 2 \mathrm{~cm} / \mathrm{s}, p<0.001$, thời gian co đẳng tích giảm (mean $2.5 \pm 1.0 \mathrm{~cm} / \mathrm{s} 2$ vs mean $2.1 \pm 0.7 \mathrm{~cm} / \mathrm{s} 2, \mathrm{p}=0.022$ ). Chức năng thất phải toàn bộ ở những bệnh nhân có PASP trên $50 \mathrm{mmHg}$ có thay đổi rõ rệt sau phẫu thuật hơn những bệnh nhân có $P A S P<50$ $\mathrm{mmHg}^{7}$. Qua những phân tích trên, có thể thấy kết quả nghiên cứu của chúng tôi không có nhiêu khác biệt so với các tác giả trên thế giới.

\section{KẾT LUÂ̂N}

Phẫu thuật sửa van 2 lá sẽ góp phần cải thiện chức năng thất phải ở đánh giá ngắn hạn.

\section{TÀI LIẸU THAM KHẢO}

1. Ta Thị Dinh, Nguyễn Thị Thu Hoài \& Đỗ Doãn Lợi. Đánh giá hình thái và mức độ hở 2 lá bằng siêu âm tim 2D, 3D ở bệnh nhân hở hai lá có chì đinh phẫu thuât. (Đai hoć Y Hà Nội, 2017).

2. Nguyên Thị Thu Hoài. Vai trò của siêu âm tim trong can thiệp bệnh lý hở hai lá. Kỷ yếu hội nghị Tim mạch toàn quốc 23-56 (2016).

3. Le Tourneau, T. et al. Right ventricular systolic function in organic mitral regurgitation: impact of biventricular impairment. Circulation127, 15971608 (2013).

4. Chrustowicz, A., Gackowski, A., El-Massri, N., Sadowski, J. \& Piwowarska, W. Preoperative right ventricular function in patients with organic mitral regurgitation. Echocardiography 27, 282-285 (2010).

5. Borer, J. S., Hochreiter, C. \& Rosen, S. Right ventricular function in severe non-ischaemic mitral insufficiency. Eur Heart J12 Suppl B, 22-25 (1991).

6. Sun, X., Ellis, J., Kanda, L. \& Corso, P. J. The role of right ventricular function in mitral valve surgery. Heart Surg Forum16, E170-176 (2013).

7. Hyllén, S. et al. Right Ventricular Performance After Valve Repair for Chronic Degenerative Mitral Regurgitation. The Annals of Thoracic Surgery98, 2023-2030 (2014). 